\title{
ÁNGEL RAMA, ANTONIO CANDIDO Y LOS CONCEPTOS DE SISTEMA Y TRADICIÓN EN LA TEORÍA CRÍTICA LATINOAMERICANA MODERNA*
}

\section{Grínor Rojo**}

Resumen: Estudio sobre los conceptos de sistema y tradición en la teoría crítica moderna de América Latina, desde la perspectiva de los ensayos de Ángel Rama y Antonio Candido.**

La cordial y fructífera relación que mantuvieron Ángel Rama y Antonio Candido a los largo de más de dos décadas a mí me trae a la memoria otra anterior no menos cordial y no menos fructífera, me refiero a la de Alfonso Reyes con Pedro Henríquez Ureña ${ }^{1}$. Habiéndose dado cada uno de esos dos diálogos en un tiempo distinto, se advierte en ambos una comunidad de ideales, lecturas compartidas y aspiraciones y realizaciones afines. Todo ello nos está demostrando que desde el tercer decenio del siglo $\mathrm{XX}$ por lo menos, como

- Recebido para publicação em junho de 2007.

* Universidade do Chile.

.* Este artículo contiene la primera parte del capítulo VI, "Los dos pisos de un edificio que mal que mal tiene tres: la teoría crítica de Ángel Rama", en un libro en preparación sobre el desarrollo de la teoría crítica latinoamericana moderna.

1 Una publicación reciente, que sigue la pista de los inicios de esa amistad, es la de Víctor Barrera Enderle. De la amistad literaria (Ensayo sobre la genealogía de una amistad. Alfonso Reyes / Pedro Henríquez Ureña, 1906-1914). Monterrey. Universidad Autónoma de Nuevo León, 2006. 
Henríquez Ureña lo percibió correctamente en $1926^{2}$, y con una intensidad que veremos incrementarse después de la década del cincuenta, el campo de la teoría crítica latinoamericana moderna se ha configurado ya de una manera estable $o$, para ponerlo ahora en los términos de Antonio Candido, que no resulta exagerado decir que existen, a esas alturas, entre nosotros, "sistema" y "tradición" a este respecto.

Transcurrido casi medio siglo desde que ellos se vieron las caras por primera vez, la amistad literaria entre Candido y Rama podemos leerla hoy como una carrera de postas. Para adelantar nada más que la línea gruesa de.su desarrollo (la verdad es que las conexiones son múltiples e incluyen hasta una correspondencia que se guarda en el archivo de Rama en Montevideo), se escuchan ecos explícitos de la Formação de la literatura brasileira (Momentos decisivos), el libro del 59 de Candido, en "Diez problemas para el novelista latinoamericano", el muchas veces reeditado ensayo de Rama de 1964, así como también en Rubén Darío y el modernismo. Circunstancia socioeconómica de un arte americano, su libro de 1970, y hasta llegar a los prólogos a los dos volúmenes de Clásicos hispanoamericanos, de 1982 y 1983. Eigual cosa podemos comprobar que ocurre entre Literatura y sociedad y "Literatura y subdesarrollo", los trabajos del brasileño de 1965 y 1972 respectivamente, y dos libros de Rama de tanta trascendencia como son Los gauchipoliticos rioplatenses. Literatura y sociedad (repárese en el título, el que hacia atrás nos está reenviando en la dirección de otro igualmente famoso, éste de Raymond Williams, Culture and Society, de 1958) y Transculturación narrativa en América Latina, uno de 1976 y el otro de 1982.

2 En las páginas finales de "El descontento y la promesa". Seis ensayos en busca de nuestra expresión en Obra critica, ed. Emma Susana Speratti Piñero. México y Buenos Aires. Fondo de Cultura Económica, 1960, pp. 252-253. 
Todo ello ha sido causa de que uno delos investigadores de la obra del intelectual uruguayo aquilate esa amistad suya con Candido con una indisimulada dosis de entusiasmo escribiendo que para Rama ella "Significó la posibilidad de acercarse al más renovador de los estudiosos de una literatura desconocida paraloshispanoamericanosy, depaso, leposibilitó el aprendizaje directo de algunas nociones que contribuirán a un método que, muy especialmente en esa época, se empeñaba en edificar" ${ }^{\prime \prime}$. La amistad partió, por lo que yo sé, con un viaje de Candido a Montevideo, en febrero de 1960, a dictar clases en la escuela de verano de la Universidad de la República, y con una entrevista que Rama le hizo en esa oportunidad, la que se publicó en el número 19 de Marcha ${ }^{4}$. A esa entrevista siguió (es casi seguro. No he encontrado el dato exacto, pero me puedo dar cuenta de sus consecuencias) la lectura que Rama hizo de la Formação... y un artículo que se titula "La construcción de una literatura", en el que el magisterio del brasileño deviene ostensible.

En aquel artículo, subproducto de una típica encuesta periodística entre los escritores uruguayos acerca del "año literario", lo que motivaba a Rama principalmente era, por cierto, bastante menos trivial. El punto de mira de su prosa era allí la literatura toda del Uruguay, vista ella no como un fenómeno más de la naturaleza sino como algo que se construye, como una "estructura histórica", esto es, con su correspondiente política de inclusiones y exclusiones. $\mathrm{O}$, mejor dicho, como el proceso de la articulación de un corpus bajo

3 Pablo Rocca. "Notas sobreel diálogo intelectual Rama/Candido" en Raúl Antelo, ed. Antonio Candido y los estudios latinoamericanos. Pittsburgh. Universidad de Pittsburgh. Instituto Internacional de Literatura Iberoamericana, 2001, p. 47.

4 "Antonio Candido. La nueva crítica brasileña". Marcha, 19 (1960), 23. Reproducida en Antelo, ed. Antonio Candido y los estudios latinoemericanos, 68-70. 
la forma de un canon, desde el pasado decimonónico hasta ese presente en el que él escribe. Eso es lo que él denominó la "construcción" (recordemos que con un designio análogo Candido había usado el término "formación") de la literatura uruguaya dentro de un marco contextual constituido en aquella circunstancia específica por algunos factores globales, "la cada vez más estrecha interacción de la civilización contemporánea", y otros domésticos, un "momento decisivo", de "grave crisis" política, económica moral "y hasta institucional" en el desarrollo histórico del Uruguay $^{5}$. Esto estaría siendo acompañando por la sólo. en apariencia paradójica "plenitud" literaria de una generación de escritores ya maduros y la entrada en la arena literaria de "nuevas promociones" (la marca del generacionismo diltheyano $y$ orteguiano, reflejo condicionado de la historiografía literaria latinoamericana de aquella época y sobre todo en el ámbito del comentario en los medios, no se nos debe escapar en este punto del discurso de Rama ${ }^{6}$ ).

Así, para entender bien lo que ha acontecido y continúa aconteciendo con la práctica literaria de sus compatriotas es que Rama recurre por primera vez en 1960 a los servicios teóricos y metodológicos de Candido: "una buena definición

5 Ángel Rama. "La construcciôn de una literatura". Originalmente en Marcha, 1041 (1960). 24-26. Reproducida en Antelo, ed. Antonio Candido y los estudios latinoemericanos, 21-34. En las otras citas de este artículo, daremos sólo el número de página entre paréntesis.

6 Incluso un crítico marxista bastante riguroso, como José Antonio Portuondo, no sintió que él incurriera en contradicción al declararse partidario de ese generacionismo en diversas oportunidades, particularmente en "Períodos' y 'generaciones' en la historiografía literaria hispanoamericana". Cuadernos Americanos, 3 (1948), 231-252; y en el libro La historia y las generaciones. Santiago de Cuba. Manigua, 1958. Me he referido a este asunto en "Práctica de la literatura, historia de la literatura y modernidad literaria en América Latina" en Crítica del exilio. Ensayos sobre literatura latinoamericana actual, 1989, p. 20 et sqq. 
de lo que entendemos por 'literatura', la ha utilizado el crítico brasileño Antonio Candido, como base para su libro Formación de la literatura brasileña y el cotejo es útil ya que se trata de una literatura marginal, fruto de coloniaje, como la uruguaya" (23). Le parece particularmente rendidora a Rama, en la Formação... de Candido, la noción de "sistema", que como nosotros esperamos haberlo demostrado en otra parte es fundamental tanto en el desarrollo de la teoría crítica metropolitana moderna como en la obra temprana del brasileño, y la aplicación que de ella él puede hacer a la historia de la literatura uruguaya.

Rama siente que ni la historia ni la historiografía literaria uruguayas debieran darse por satisfechas con la mera comprobación de que en el país se han producido algunas obras literarias de cierta excelencia: "No basta que haya obras literarias, buenas y exitosas, para que exista una literatura. Para alcanzar tal denominación, las distintas obras literarias y los movimientos estéticos deben responder a una estructura interior armónica, con continuidad creadora, con afán de futuro, con vida real que responda a una necesidad de la sociedad en que funcionan" (22). Y precisa: "Mientras que a las grandes creaciones sólo podemos esperarlas y desearlas, y responden a los dones íntimos de los individuos, en cambio podemos crear esto: una literatura". '(23). Desde este otro punto de vista, tendría que darse por supuesto que a la "literatura" todo aquel que se le acerque con el propósito de interrogarla historiográfica y/o críticamente la va a estar asumiendo como una suerte de corpus canónico, o sea como los frutos de una práctica que se integra funcionalmente en el interior de un sistema y que ahí da origen a "un servicio público muy sui generis", el de los escritores, los que cumplen "una tarea social" cuya correcta comprensión estima entonces Rama que se alcanza mejor prestando oído a las recomendaciones del 
Sartre de ¿Qué es la literatura? que por la vía del "marxismo dogmático" (Ibid.).

Algo que me llama la atención en este artículo, que a Rama no le llega desde su lectura de Candido sino desde algún otro sitio cuya localización no logro discernir con absoluta claridad, pero que bien podría obedecer a sus preferencias personales y que de todas maneras lo prefigura en la dirección que va a tomar su labor algunos años después, es su sospecha de que la totalidad socioliteraria no tiene por qué coincidir con "la patria", ya que a menudo ella responde "a regiones que superan fronteras" (22). Esa conjetura, que da al traste con cualquier pretensión de atribuirle uniformidad y linealidad a su comprensión del todo social y cultural, que va a tener una enorme gravitación sobre su pensamiento crítico posterior y sobre el de varios otros de sus colegas y contemporáneos, como es el caso de Antonio Cornejo Polar, Rama la activa en este artículo a través de su escrutinio del panorama literario uruguayo, al que él diagnostica partido en dos: de un lado la literatura urbana, que no constituye aún un "sistema", en la acepción que Candido le diera a la palabra, y del otro la producción gauchesca, que sí lo ha hecho. El éxito que esta última ha tenido en la forja de su propia sistematicidad se explicaría, a su juicio, "por la más pronta y feliz creación de 'arquetipos literarios' - tuvo más tiempo para hacerlo- que ya aparecen establecidos hace un siglo, usando de la invención de un lenguaje y de una tonalidad expresiva". Sin embargo, cree él asimismo que, "por encima de esta admirable operación literaria hay una explicación aún más convincente: si los gauchescos pudieron crear una literatura lo debieron a que fueron casi los únicos que eligieron decididamente un público [...] La literatura urbana, en cambio, no sólo no logró constituir el 'sistema', sino que se ha ido desprendiendo de su 
escaso público - los últimos decenios han sido trágicos-; así el escritor trabajó para la élite de escritores, con el ojo puesto en el 'hombre universal' y en el 'hombre del futuro'. No obtuvo ni uno ni otro" (25).

Como vemos, la gauchesca cumple, en la opinión de este Ángel Rama de 1960, con las tres exigencias del triángulo sistémico que Candido, extrapolándolo desde la Teoría del lenguaje de Bühler, había postulado en el 57/59 como requisito indispensable para la existencia de una "literatura". Triángulo compuesto, para citar ahora las palabras del autor de la Formação..., por "la existencia de un conjunto de productores literarios, más o menos conscientes de su papel; un conjunto de receptores, que forman los distintos tipos de público sin los cuales la obra no vive; y un mecanismo transmisor (de modo general, un lenguaje que se traduce en estilos), que vincula a los unos con los otros". Y agrega: "El conjunto de los tres elementos da lugar a un tipo de comunicación interhumana, la literatura, que aparece, bajo este ángulo, como sistema simbólico por medio del cual las veleidades más profundas del individuo se transforman en elementos de contacto entre los hombres y de interpretación de las diferentes esferas de la realidad"7. Y esto es aquello cuya existencia Rama pone en duda que pueda verificarse con respecto de la literatura de ciudad que se ha venido produciendo en el Uruguay hasta ese instante. Especialmente grave le parece, como hemos visto, el desajuste que él detecta en el Uruguay entre el horizonte de expectativas del público urbano lector (el "escaso" público urbano lector) y lo que los escritores locales se empeñan vanamente en endilgarle.

7 Antonio Candido. "Introdução" a Formação de la literatura brasileira (Momentos decisivos). São Paulo. Martins, 1959, p. 23. 
He ahí pues, en medio de un intento de aplicación de las ideas historiográficas de Antonio Candido a la literatura uruguaya, el doble carril a través del cual se moviliza una porción sustancial de su pensamiento y escritura más tardíos. En efecto, si nosotros nos desplazamos ahora hacia el futuro, hasta llegar a los que van a ser probablemente sus libros de mayor impacto, Transculturación narrativa en América Latina, del 82, y el póstumo La ciudad letrada, del 84, poco costará que nos percatemos de que los presupuestos básicos para la composición de ambos volúmenes son los mismos que se encuentran en el brevísimo artículo que yo acabo de comențar y que juntos conforman algo así como los dos pisos de un edificio que, como cuesta muy poco comprobarlo, en realidad tiene tres, aunque sobre el tercero de ellos él pase el codo con un ademán tan resuelto como reprobatorio. La oposición rural-urbano o, si se quiere, iletrado-letrado, que es la que sostiene la reflexión de Rama sobre la literatura uruguaya en 1960, seguirá proporcionándole uno de los ejes de su pensamiento literario (y no sólo de su pensamiento literario) hasta el fin de sus días. Es más: yo me atrevo a asegurar que también la asimetría que Rama detecta en aquel artículo, en lo concerniente al estatuto de la mencionada oposición en las dos mitades de la literatura de su país, se reproduce, a escala ampliada, en las consideraciones que vendrán posteriormente acerca del estatuto de la producción literaria continental.

La mudanza entre el articulillo de 1960 y "Diez problemas para el novelista latinoamericano", el largo y enjundioso ensayo de 1964, podemos medirla en términos de la distancia que separa a lo nacional-local de lo continentallatinoamericano, pero sin que ello entrañe un cambio de perspectiva. El pensamiento teórico de Antonio Candido permea también el ensayo del 64 en varios de sus capítulos, 
pero donde esa influencia se nota con más fuerza, y así lo reconoce el propio Rama, es en el que se titula "El novelista y la literatura nacional". Las ideas más potentes que Rama había desenfundado cuatro años antes, al ocuparse de la literatura uruguaya, se reflotan de nuevo aquí, pero ahora para dar cuenta de lo que acontece en la materia en otros países de la región. Apoyándose una vez más en las exigencias que se desprenden de la noción candidiana de sistema, concluirá que "salvo el caso explícito, concreto, del Brasil, y salvo atisbos en México y en Buenos Aires, no se registra [en los otros países de la región latinoamericana] la existencia de una literatura nacional nítidamente diferenciable, con su estructura interna propia, su constelación temática, su sucesión estilística, sus peculiares operaciones intelectuales históricamente reconocibles". A eso se agregaría el hecho, que según él se encontraría a salvo de cualquier controversia, de que, "debido a la balcanización política de América Latina por obra de los imperialismos, las oligarquías locales y las falsas estructuras administrativas del coloniaje", las entidades nacionales devienen entre nosotros, además de espurias, entorpecedoras de la actuación de otras configuraciones más auténticas, bloqueando "la natural expansión y desarrollo de las comarcas semejantes donde los elementos étnicos, la naturaleza, las formas espontáneas de la sociabilidad, las tradiciones de la cultura popular, convergen en parecidas formas de creación literaria". $Y$ aclara finalmente: "Estas comarcas - no sólo naturales sino también culturales - son desfiguradas por la balcanización política, pero sin embargo debe reconocerse en ellas elementos de suyo tan poderosos como para que hayan sobrevivido, otorgándoles unidad característica, en este siglo y medio de vida independiente, dividida, de América Latina. Más aún: si han continuado siendo notorias y notables las aproximaciones 
de un país con otro dentro de la misma comarca, ello se debe en primer término a la literatura, sobre todo a aquella - novela o poesía- más embebida en las fuentes populares". Las "comarcas" en cuestión, al menos las que él nombra en este texto específico, son el Tahuantisuyo, la comarca "pampeana" y la "caribeña".

Con todo, el hecho de que existan en América Latina semejantes comarcas culturales, unificadas y más o menos compactas, en unos cuantos puntos de un mapa dentro del cual lo que prima es la fragmentación política, no constituye garantía de la existencia hacia adentro de las primeras de literațuras orgánicamente constituidas en el sentido candidiano. Rama estima que para que eso ocurra la unidad de cultura que se observa en las regiones es una condición necesaria, aunque no suficiente. Como veíamos, la brecha que en la mayor parte de los países de América Latina separa a las "manifestaciones literarias" aisladas, como las denominó Candido, algunas de gran valor sin duda, de una "literatura nacional autónoma", a Rama le parece en estas líneas si es que no insalvable del todo, muy difícil de franquear. Pero tampoco las fortalezas que él descubría en el regionalismo "pampeano", por ejemplo, en el que depositaba sus esperanzas en el artículo del sesenta, como posible patrocinador de un sistema literario completo, a través del corpus de la poesía gauchesca, son objeto aquí de ese mismo reclamo.

Paradójicamente, sin embargo, en las "Diez preguntas para el novelista latinoamericano" Rama argumenta que al sur del Río Bravo "ya es posible hablar de una cultura latinoamericana (o hispanoamericana) con direcciones

8 Ángel Rama. "Diez problemas para el novelista latinoamericano" en Juan Loveluck, ed. La novela hispanoamericana. Santiago de Chile. Universitaria, 1969, p. 292. 
y valores propios, tónicas y medios característicos", aun cuando resulte "bastante más difícil registrar la autonomía y la mera existencia de las literaturas nacionales" ${ }^{\prime \prime}$. Es como si, en la imposibilidad o la cuasi imposibilidad de encontrar los "sistemas" que él anda buscando en las literaturas nacionales (la excepción sería el Brasil, como hemos visto), fuesen entonces las literaturas "comarcanas", por un lado, y la literatura regional latinoamericana (regional, no regionalista, que es algo distinto), por el otro, las que presentan las mejores opciones para concretar ese deseo ${ }^{10}$.

Mi impresión es que la segunda de estas posibles. opciones constituye el principal acicate para la escritura de Rubén Darío y el modernismo..., el libro de 1970, tan importante también por otros motivos (de hecho, es el libro que revoluciona la crítica sobre esta tendencia literaria hispanoamericana, entre el dictamen de quienes la vilipendieron desde su nacimiento por escapista y mimética y una estimación en la que ni uno ni otro de tales reproches es o será ya más sustentable ${ }^{11}$ ). Quiero

$9 \quad$ Ibid., 291-292.

10 En las primeras páginas de " $\mathrm{El}$ indigenismo y las literaturas heterogéneas. Su doble estatuto sociocultural" (1977), Antonio Cornejo Polar reproduce este argumento casi verbatim. Verlo en: Sobre literatura y crítica latinoamericanas. Caracas. Facultad de Humanidades y Educación. Universidad Central de Venezuela, 1982, p. 67 et sqq.

11 No es mi intención hacer un análisis exhatistivo de este libro, pero no es inoficioso recalcar aquí que Rubén Dario y el modernismo... inicia una nueva época en el estudio de este tema fundamental de las letras de Hispanoamérica $\mathrm{y}$, más precisamente, en el estudio del modernismo en relación con las circunstancias en que el mismo aparece. Lo que Rama tiene detrás suyo es, en este aspecto y como lo indicábamos arriba, una tesis doble. Según ella, los modernistas le habrían dado la espalda a su tiempo, produciendo un arte escapista, por la vía de un exotísmo de signo variado (desde aquel que se basa en el amor por el lujo contemporáneo hasta el descubrimiento de culturas alternativas o el cultivo de la imaginación pura) y mimético, de copia sobre todo del arte europeo, especialmente de la poesia postromántica francesa. Este 
decir con esto que no me parece descaminado entender que lo esencial de aquel libro se reduce a una tentativa, por parte de Rama, de establecer ni más ni menos que los orígenes de la moderna tradición de la literatura de América Latina. No habiendo encontrado los elementos para completar esa tarea ni en su propio país ni en ningún otro, y poniendo por el momento entre paréntesis el tema de las "comarcas culturales", sobre el que regresará sin embargo dentro de poco, lo que escoge en Rubén Darío y el modernismo... es una perspectiva continental at large. Así, practicando una operación similar (pero de más largos alcances todavía) a la que practicara Antonio Candido en la Formação... y contradiciendo un raciocinio que se había hecho materia de sentido común entre la crítica continental clasemediera y que situaba los orígenes de la literatura hispanoamericana moderna en las transformaciones

punto de vista castigador es, aunque no exclusivamente (alguien que es de otra escuela, pero que sin embargo lo comparte es Manuel Pedro González), el de los críticos marxistas de los años cuarenta, cincuenta y sesenta, representados egregiamente por el cubano Juan Marinello. Rama reacciona contra las dos direcciones de esta tesis. Para él, el modernismo ni es escapista ni es imitativo. En cuanto a lo primero, demostrará cómo, e inevitablemente, el modernismo responde a su tiempo incorporando la lógica productiva del capitalismo (como veremos, en una época posterior, se atreverá a postular también la lógica política de la democracia contra la acusación de "aristocratismo"); y en cuanto a lo segundo, esgrimirá la contratesis que encabeza su libro: "El fin que Rubén Darío se propuso fue prácticamente el mismo a que tendieron los últimos neoclásicos y primeros románticos de la época de la independencia: la autonomía poética de la América española". Rubén Dario y el modernismo. Caracas y Barcelona. Alfadil, 1985, p. 5 [esta edición inexplicablemente, le borra al libro el subtítulo original: "Circunstancia socioeconómica de un arte americano"]. Ergo: el modernismo no sería un arte de imitación, sino todo lo contrario: el modernismo lo que pretende es independizar, e independiza en efecto, estéticamente, a la América española. Todo esto está dicho con vistas al planteo básico del libro, el que pone al modernismo como cabeza de serie de la modernidad literaria hispanoamericana, y que es un planteo con el que Rama siguió trabajando en una serie de estudios de gran calidad y que rematan en el póstumo Las máscaras democráticas del modernismo (1984). 
desencadenadas por la vanguardia desde la segunda o tercera década del siglo $X X^{12}$, Rama va a volver la mirada hacia atrás $\mathrm{y}$ a argüir que es el achievement de los modernistas el que amerita tamaña distinción. Y esto por su espíritu fundador genuino, porque entre nosotros los modernistas fueron los primeros que dotaron de "autonomía" a la literatura regional de Hispanoamérica, confiriéndole un perfil propio dentro de un "orbe cultural", el de fines del siglo XIX, que también fue propio, aunque al mismo tiempo "con la implícita aceptación de la participación de la nueva literatura en el conglomerado mayor de la civilización europea, que tenía sus raíces en el mundo grecolatino"13. Los grandes desplazamientos de Darío, de Nicaragua a Chile, de Chile a la Argentina, de la Argentina a Europa y de Europa de vuelta otra vez en el territorio americano, serán leídos por Rama en este contexto: como los viajes del vate epónimo por el "orbe" moderno hispanoamericano y mundial.

Aunque sin tomarse la molestia de poner la acostumbrada nota al pie de página, Rama parafrasea a Candido en el libro del 70 y expresa: "Una literatura es entendida, aquí, no como una serie de obras de valor, sino como un sistema coherente con su repertorio de temas, formas, medios expresivos, vocabularios, inflexiones lingüísticas, con la existencia real de un público consumidor vinculado a los creadores, con un conjunto de escritores que atienden las necesidades de ese público y que por lo tanto manejan los grandes problemas literarios y socioculturales. Los tres

12 He hecho presente el origen clasista de este error en un ensayo de autocrítica de 1982. Véase: Grínor Rojo. "En torno a la llamada generación de dramaturgos hispanoamericanos de 1927 más unas pocas observaciones sobre el teatro argentino moderno (Elementos de autocrítica)". Revista de Crítica Literaria Latinoamericana, 16 (1982), 67-76.

13 Rubén Dario y el modernismo..., 5. 
sectores componen una estructura de desarrollo histórico que por lo mismo sobrevive a las distintas etapas de integración de sus partes, imponiendo la permanencia del pasado - de un pasado vivo, que pesa y actúa- sobre las diversas inflexiones de un sucesivo presente ${ }^{\prime \prime 14}$.

También interesante es que en Rubén Darío y el modernismo... Rama complemente el triángulo de Candido con un esfuerzo de profundización en la naturaleza del nexo sociocultural de los escritores mismos. Habiendo ya reconocido (aunque púdicamente, sin abusar del término) que la base de la estructura económica de la época modernista es el capitalismo, el que se ha impuesto para entonces como el modo de producción hegemónica en las economías de América Latina y al que él define en términos de "subjetivismo económico" (sic), Rama argumentará que ese subjetivismo capitalista empalma con el subjetivismo literario modernista. Práctica capitalista y práctica literaria modernista serían ambas "subjetivas" o "subjetivistas" y, por lo mismo, empeñadas, entre otras cosas, en procesos de continua y ávida renovación. No es quela práctica modernista "refleje" la práctica capitalista, sin embargo, puesto que la conexión que Rama postula no es temática o "de contenidos". La práctica modernista actúa como la práctica capitalista porque cualesquiera sean los contenidos que comunica, dentro su propia esfera de funcionamiento y con la lógica que le es propia, internaliza los mecanismos y valores del capitalismo: técnica, rigor disciplinario, etc. Al cabo, puede suceder que los modernistas escriban contra el capitalismo, como Darío en "El rey burgués", por ejemplo, pero lo harán siempre con las armas del capitalismo. En cuanto a la dimensión cultural, ella se habría dado en los productos literarios del modernismo en la forma de una aspiración a la "isocronía"

${ }^{14}$ Ibid., 11-12. 
(a la coincidencia entre el tiempo cultural de Europa y el de América) a la vez que haciéndose eco de la intensificación cultural y la división del trabajo, que obedecieron también (de maneras específicas, claro está) a las determinaciones introducidas en la praxis de esos intelectuales por la posición dominante del capital.

Con todo esto lo que Rama estaba tratando de conseguir en 1970 era una plataforma teórica que le permitiese dar cuenta del enlace entre literatura y sociedad, reemplazando la estética neoleninista del reflejo, que había sido el punto de partida de los teóricos de izquierda durante la primera mitad del siglo $X X$, entre los cuales Lukács es la figura descollante y la más lúcida, por una estética productivista. Uno capta la voluntad del crítico uruguayo de desmarcarse de las reducciones del sociologismo, echando mano, por ejemplo, de autores como Ernst Fisher (La necesidad del arte) o Walter Benjamin (un Benjamin cuyos Schriften él todavía lee en francés y un tanto a la ligera). Pero no será sino hasta tres años después, en "Sistema literario y sistema social en Hispanoamérica", que elabore estas intenciones con una mayor sofisticación al hacer uso ahora de una matriz epistémica que acepta la asistencia de Tinianov junto con la de Castoriadis y Goldmann. Especula Rama entonces que un período de literatura está compuesto siempre por "secuencias" literarias diferentes (si bien no desprovistas de vasos comunicantes), a las que flanquean "dos discursos paralelos, de naturaleza emparentable, porque ambos pertenecen a las operaciones de la cultura"15. Esos dos discursos son, según explica, el "lingüístico", que estaría hecho de "comportamientos" variados, sobre todo en el "habla", y el

15 Ángel Rama. "Sistema literario y sistema social en Hispanoamérica" en Fernando Alegría, ed. Literatura y praxis en América Latina. Caracas. Monte Avila, 1975, p. 81. Mis otras citas de este artículko irán en el texto entre paréntesis. 
del "imaginario social" (90 y 93). Este otro "es asumido por la literatura en forma análoga a la asunción que ella hace del discurso lingüístico: valor estructurante y a la vez indicial del grupo o clase que en ese 'imaginario social' se ve representado" (93). En cuanto al grupo social, a la clase, éste/a, "además de vivir concretamente su situación, sus intereses, sus demandas y sus problemas, a partir de todo ello genera una construcción de tipo ideológico que, siguiendo a Lucien Goldmann, podemos designar como una cosmovisión" (Ibid.).

Respecto del modernismo hispanoamericano, su "período" correspondería al que Halperin Donghi denomina del "pacto neocolonial, que para el historiador argentino se abre hacia 1880 y entra en decidida crisis hacia 1930" (98). Durante esta época, contemporáneos de otros escritores que se encuentran insertos en "secuencias literarias" que son diferentes a la de ellos (las secuencias del criollismo y la gauchesca son dos ejemplos claros), los modernistas van a ser los primeros en producirla "autonomía" dela nuestraliteratura. Autonomía que lo es en primer lugar para ser ella misma, para ser una literatura que se ha hecho por fin merecedora del nombre de tal y para, en segundo lugar, habiendo alcanzado ya ese estatuto, prolongarse en el despliegue sostenido de una tradición "que pesa y actúa", tradición que acabará convirtiéndola en una rama legítima (un "galho", había sido la expresión portuguesa de Candido) en el árbol literario metropolitano. Sin desdecirse, manteniendo su adhesión al magisterio de Candido y reconociendo su influencia esta vez expresamente, pero también recombinándola al introducir en la propuesta del brasileño nuevos niveles de complejidad, reincide Rama en el tema en el 83: "Debe reconocerse a los escritores de la modernización el rango de fundadores de la autonomía literaria latinoamericana, en este nuevo nacimiento 
de la región. En el mismo tiempo en que surgen las primeras historias de las literaturas nacionales, vinculando el pasado colonial con los años de la independencia y fijando fronteras frecuentemente artificiales con las literaturas de los países vecinos, la intercomunicación y la integración en el marco literario occidental instauran la novedad de un sistema literario latinoamericano que, aunque débilmente trazado en la época, dependiendo todavía de las pulsiones externas, no haría sino desarrollarse en las décadas posteriores y concluir en el robusto sistema contemporáneo". $\mathrm{Y}$, después, pero afinando su tesis un poco más: "Es en la modernización que se fragua el sistema literario hispanoamericano (aunque se denomine a sí mismo latinoamericano, cosa que no lo será hasta la posterior y muy reciente incorporación de las letras brasileñas)" ${ }^{\prime 16}$.

Darío y los suyos habrían consumado, por lo tanto, la hazaña de dar nacimiento a un corpus sistemático de literatura, el que, prospectivándose más allá del radio de la acción directa de sus perpetradores, terminó transformándose en el punto de arranque de la modernidad poética ( $y$, en general, literaria) de la América Hispana. No está demás que yo insista en este momento en que, con un fraseo que está transferido casi al pie de la letra desde la "Introducción" de Candido del $57 / 59$, cuando Rama hablaba ya en 1970 del modo de "decir" los contenidos poéticos de la literatura modernista, modo de decir que se encuentra por encima del segundo elemento del sistema tripartito bühleriano-candidiano, lo estaba pensando

16 "La modernización literaria latinoamericana (1870-1910)" en Ángel Rama. La crítica de la cultura en América Latina, eds. Saúl Sosnowski y Tomás Eloy Martínez. Caracas. Ayacucho, 1985, p. 87. El subrayado es suyo. Se trata de una reproducción del "Prólogo" a Clásicos hispanoamericanos, Vol. II. Barcelona. Círculo de Lectores, 1983. 
en términos de "temas", "formas", "medios expresivos", "vocabularios" e "inflexiones lingüísticas"17.

Rama no dejó de trabajar en el modernismo hasta que en 1983 lo pilló la muerte en España. No cabe duda de que en el modernismo había hallado una clave que le abría un sinúmero de puertas y él no cesó de aprovecharla. Personalmente, debo decir que me parece que no cabe duda que, junto con el brillo mismo de la literatura modernista, que en la pluma de Darío era para él el fruto de "un don poético superior"18, lo que más lo seducía en esta empresa era el problema (y la oportunidad) historiográfico/a que ella le deparaba o, dicho con. otras palabras, el tipo de problema y el tipo de oportunidad que Candido había puesto frente a sus ojos en Montevideo, en el verano de 1960.

Quería Rama reabrir, sirviéndose para ello de los resultados de su pesquisa modernista, el debate sobre la unidad de Hispanoamérica en la segunda mitad del siglo XX (al menos el de esa unidad, la unidad de "Hispanoamérica". La oscilación entre Hispanoamérica y América Latina se da en el vocabulario de Ángel Rama como en el de varios otros de nuestros pensadores tanto literarios como no literarios de aquella época, aunque el titubeo se vaya resolviendo a favor del segundo de los dos vocablos con el correr de los años), si bien pensaba que tenía que hacerlo desde el punto de vista de su literatura. Le asistían reservas análogas a las que manifestaron Martí y Mariátegui en cuanto a la validez de los constructos nacionales, los que se edificaron durante el siglo XIX, que le parecían hechizos y distorsionadores de las realidades

17 Recordemos que Candido había hablado de "lengua", "temas", "imágenes" o, en el mismo sentido, de un "mecanismo transmisor (de modo general, un lenguaje que se traduce en estilos)".

18 Rubén Dario y el modernismo, 6. 
colectivas que ellos se preciaban de representar, pero podía prescindir de esas reservas en lo tocante a la efectividad y eficacia de una cultura continental (acaso porque quería voluntarísticamente prescindir de ellas), abarcadora de todos los países en que se habla español, cuando no y directamente, con el significado socioeconómico que el latinoamericanismo adquirió entre los más prestigiosos de nuestros intelectuales de los años sesenta del siglo XX, desde Celso Furtado a Agustín Cueva. América Latina vista ya no como una región de pueblos usuarios todos ellos de un mismo idioma, lo que jamás fue así por otra parte, y ni siquiera en el interior de la (llamada) América Hispana, sino como una región de pueblos que comparten condiciones similares de opresión y pobreza.

En algún momento de su trayectoria intelectual, lo más probable es que con posterioridad al triunfo de la Revolución Cubana, pero sobre todo en los años de su exilio y definitivamente desde la publicación del artículo "Un proceso autonómico: de las literaturas nacionales a la literatura latinoamericana"19, Rama asume esta segunda perspectiva, empapada de un latinoamericanismo fogoso aunque no provinciano, a la que juzga requerida de "un discurso crítico que abarque todos los países que se designan con el rótulo América Latina"20. Entonces es cuando desempolva el tema de nuestra unidad, poniendo con ello su firma en la propuesta bolivariana, aun cuando para su propio consumo la reoriente hacia el plano doble de la cultura y la literatura. Más que en un descendiente de Bolívar se transformará a contar de aquellas fechas en un discípulo de Bello y, junto con Bello, de quien iba a ser la primera y más grande de sus figuras

19 "Un proceso autonómico: de las literaturas nacionales a la literatura latinoamericana". Rio Piedras, 5-6 (1974-1975).

20 "La modernización...", 90. 
tutelares: Pedro Henríquez Ureña. Puede que le reproche por ahí al dominicano un cierto apresuramiento al decretar la profesionalización del escritor hispanoamericano antes de que ella se hubiese consolidado plenamente ${ }^{21}$, pero eso no le impidió editar junto a Rafael Gutiérrez Girardot el volumen de Ayacucho con sus obras selectas. El hecho es que constituiría un acto de ceguera no ver que el ejemplo y las ideas de don Pedro tuvieron sobre él un impacto profundo e inclusive en lo que toca a la aparición en la América Hispánica, a partir de la poética dariana, de un quehacer literario especializado. Cualesquiera hayan sido las dificultades impuestas sobre los modernistas por las limitaciones del medio y cualquiera el éxito (o la falta de él) que tuvieron al hacerlo, ellos fueron los primeros escritores que en esta zona del mundo tuvieron como meta el abocarse ciento por ciento al cultivo del belletrismo, $y$ Henríquez Ureña fue si es que no el primero en percibirlo, sí el primero en plantearse el problema de las consecuencias que ello tenía, tanto las críticas como las historiográficas. Por eso y por todas las demás razones que no son difíciles de suponer, en la última entrevista que concedió, Rama le rindió a don Pedro un homenaje, proclamando que Henríquez Ureña "fue un maestro, absolutamente un maestro de la investigación literaria y un tipo respetable [chapeau con éll] ${ }^{\prime 22}$.

21 Este reproche está ya en Rubén Dario y el modernismo..., en medio de citas profusas y en general discipulares de Las corrientes literarias en la América Hispánica. Al final de su carrera, Rama lo repite en el "Prólogo" del 83 a Clásicos hispanoamericanos: "A ese tiempo, reduciéndolo a los treinta años que van de 1890 a 1920, aunque extendiéndolo para que abarcara tanto la producción en lengua española como la del Brasil, le llamó Pedro Henríquez Ureña 'literatura pura', denominación equívoca que él fundamentó en un hecho cierto, el comienzo de la 'división del trabajo' intelectual aunque visto con óptica reductivista". "La modernización literaria..., 91. Lo mismo hace en el quinto capítulo de La ciudad letrada.

${ }^{22}$ Jesús Díaz-Caballero. "Ángel Rama y la crítica de la transculturación (Ultima 
Para todo eso, es claro que la noción candidiana de sistema le venía como anillo al dedo. Hablar de una literatura regional latinoamericana era para él hablar del "sistema" de la literatura regional latinoamericana, sistema que, como le había enseñado Candido en el libro de fines de los cincuenta, debía tener tanto un punto de despegue como una línea de continuidad. Como hemos visto, el despegue Rama lo buscó, y yo creo que lo encontró, en el modernismo. De ahí su libro del 70, antecedido por trabajos preliminares a partir de 1967, cuando publica "En el centenario de Rubén Darío: las opciones de un fundador" simultáneamente en Marcha y en Casa de Las Américas. Pero de ahí también la serie de sus ensayos posteriores acerca de aspectos particulares de la tendencia, todos ellos indispensables para su entendimiento y estimativa actuales, entre los que sobresalen el prólogo a Rubén Darío. El mundo de los sueños, de 1971, el prólogo a la edición Ayacucho de la Poesía del mismo autor, de 1977, su ampliación y enriquecimiento en "El poeta frente a la modernidad", también de ese año, "Indagación de la ideología en la poesía (Los dípticos seriados de Versos sencillos)", de 1980, o el ya mencionado prólogo al segundo volumen de Clásicos hispanoamericanos, de 1983.

La culminación de estos empeños, que como lo indiqué más arriba supusieron una relectura suya a fondo del archivo literario modernista, y una relectura que además era tremendamente polémica, porque contradecía de manera frontal lo que habian venido afirmando los críticos tradicionales que se enfrentaron con esta misma problemática (Juan Marinello, Manuel Pedro González, etc.), está en las páginas de Las máscaras democráticas del modernismo, uno de los tres libros póstumos. En ese libro, otra vez contra las opiniones de Marinello y encomendándose

entrevista)" en Moraña, ed. Angel Rama y los estudios latinoamericanos, 334. 
a (y, de paso, reivindicando) la figura de Baldomero Sanín Cano, Rama abunda en una herejía que era más transgresora aún que todas las anteriores al exigir que se le reconozca al modernismo una "impregnación americana", la que según él se desentiende del "afrancesamiento superficial" y cuyo origen sería, además -es lo que escribe y sin que le tiemble la mano-, incuestionablemente "popular", puesto "que pertenecía a la democratización que había sido una consecuencia, previsible aunque inesperada para muchos, de la modernización económica internacionalista que vivió el continente desde $1870^{\prime \prime 2}$. No sólo eso, sino que refiriéndose a la predilección modernista por los "escenarios de buen gusto, objetos refinados, cosas bellas", asegurará que todo ese aristocratismo, el mismo que enfureció a Marinello y sus colegas de inclinaciones socialistas, no era más que un disfraz de carnaval, la contracara de la "vulgaridad" incorporada en el cotidiano de nuestros países como uno de los rebotes de la modernización ${ }^{24}$.

Desde la otra punta, el sistema debía tener también una continuidad y esa continuidad se la proporcionó a Rama la evolución que, pasando por las vanguardias y las postvanguardias, va a dar no en los novelistas del boom (abominó del término, del oportunismo mercantil, la ignorancia historiográfica y el conformismo que el tal representaba desde muy pronto ${ }^{25}$ ), sino en los narradores de la

23 Ángel Rama. Las máscaras democráticas del modernismo. Montevideo. Fundación Ángel Rama, 1985, p. 183.

24 Ibid., 52.

25 Parece que su primer intento de poner las cosas en claro está en "El boom establece expresamente un recorte empobrecedor de nuestras letras, que las deforma y traiciona". Zona Franca, 16 (1972). 
"nueva narrativa hispanoamericana". Esta, la nueva narrativa hispanoamericana, fue uno de los temas que no lo dejaron tranquilo y acerca del cual escribió más páginas de las que yo pienso que eran necesarias, por lo que no tiene nada de raro que lo reencontremos en la entrevista final que le concedió a Jesús Díaz-Caballero. Dijo entonces, en 1983: "lo que llamaríamos la expansión pública de la narrativa se produjo en los 60 y evidentemente también estuvo facilitada y amparada por el clima creado por la revolución cubana y la exaltación que caracterizó esa especie de gran esperanza que marcó la década de los 60. Pero la narrativa propiamente dicha viene de antes, es decir el proceso creador de la narrativa, del que llamaríamos una nueva narrativa en América, hay que situarlo para algunos en los 40, para otros incluso a fines de los 30. Cuando en el 38 Borges escribe 'Tlön, Uqbar, Orbis Tertius', y en el 39 Onetti publica $E l$ pozo, ambos están marcando ya un cambio notorio que va ser muy visible en los 50 cuando se publiquen las grandes obras, es decir: El llano en llamas, Pedro Páramo, etc. $O$ sea, es un proceso de transformación de la narrativa que se viene desarrollando a lo largo de décadas, incluso diría que allí también tiene una enorme influencia sobre esta nueva narrativa el hecho de la expansión de la poesía que alcanzó su esplendor en la década del 20 y que fue uno de los elementos que también ayudó a transformar la escritura en prosa de la narrativa. Piensa en el caso de Asturias que escribe a lo largo de los 30 El señor Presidente ${ }^{\prime 26}$.

26 "Ángel Rama y la crítica de la transculturación (Ultima entrevista)", 326. Agrega ahí mismo: "trato de distinguir entre el proceso de la nueva narrativa -que es una creación de una nueva escritura, una nueva temática, una nueva estructura narrativa- y la expansión que sí creo que se puede llamar boom, porque es una palabra que designa fundamentalmente una operación de ampliación de mercado". Ibid. 
Pero, como sabemos, en 1964, cuando Rama publica las "Diez problemas para el novelista latinoamericano", algunas de las obras emblemáticas de esa nueva narrativa no habían conocido aún la letra impresa: La casa verde se publica en 1965, Cien años de soledad en 1967 y El obsceno pájaro de la noche en 1970. No bien aparezcan en los escaparates de las librerías, Rama les seguirá la pista con apetito de buen catador, a ellas y a las demás de la misma familia, pero sin olvidarse en ningún momento del alegato sobre su devenir geneológico, el que él retrotrae, como hemos visto, a los años treinta y cuarenta y a las obras de escritores como Borges, Onetti, Asturias, Rulfo, Arguedas y otros (contra Rodríguez Monegal, principalmente, en esta ocasión), y sobre todo al establecer el papel que esas obras desempeñaron en el articulado de una cierta "tradición literaria". Esto último era para él de capital importancia y se pone de manifiesto en los varios capítulos que forman $L a$ novela latinoamericana. Panoramas 1920-1980, entre ellos en su polémico "El 'boom' en perspectiva", a base de la ponencia que en el 79 presentó en el simposio "The Rise of the Latin American Novel", que tuvo lugar en el Wilson Center de Washington D.C.

Quedaba así constituido el mapa: existía en América Latina una tradiciónliteraria continental, cuya acta defundación se había firmado cuando la puesta en funciones del sistema modernista, en los decenios últimos del siglo XIX, sistema que evolucionaba con posterioridad hacia otros, en el archivo vanguardista y postvanguardista primero y luego en la nueva narrativa que arranca de Borges, Onetti, Rulfo y los demás. Esa corriente de desenvolvimiento sistémico o sistemático se elevaba por sobre y superaba a las correspondientes de las literaturas nacionales, que al fin y al cabo le resultaban a Rama soslayables, porque, como la historia de las naciones mismas, 
eran por lo general la obra de esos "letrados artificiales" de los que también renegó Martí en "Nuestra América", si bien mantenía buenas relaciones con otros sistemas alternativos, los de las literaturas comarcanas. Era un mapa literario de índole culturalista, según se echa de ver de inmediato, aunque sin perder por eso el enraizamiento economicosocial ni menos aún su densidad literaria. Porque lo que Ángel Rama intuía que estaba actuando en contrapunto con la evolución del sistema literario y que con el correr de los años fue conceptualizando con estrictez creciente, era el fenómeno del advenimiento y despliegue del sistema completo de nuestra episteme moderna. Rama, el joven crítico literario de Marcha, quería ser, estaba siendo ya, al ampliar los límites de su programa en esta forma, un intelectual mayor de Nuestra América. 
Resumo: Estudo sobre os conceitos de sistema $e$ tradição na teoria crítica moderna da América Latina, a partir da perspectiva dos ensaios de Ángel Rama e Antonio Candido.

\section{REFERENCIAS}

ANTELO, Raúl. (ed.) Antonio Candido y los estudios latinoemericanos (2001). Antonio Candido. La nueva crítica brasileña. Marcha, 19 (1960), 23. pag. 68-70.

BARRERA ENDERLE, Víctor. De la amistad literaria (Ensayo sobre la genealogía de una amistad. Alfonso Reyes/Pedro Henriquez Ureña, 1906-1914). Monterrey. Universidad Autónoma de Nuevo León: 2006.

CANDIDO, Antonio. Introdução. Formação de la literatura brasileira (Momentos decisivos). São Paulo: Martins, 1959, p. 23. DÍAZ-CABALLERO, Jesús. Ángel Rama y la crítica de la transculturación (Ultima entrevista). In: MORAÑA, Mabel. (ed.) Angel Rama y los estudios latinoamericanos, 334.

POLAR, Antonio Cornejo. El indigenismo y las literaturas heterogéneas. Su doble estatuto sociocultural (1977). Sobre literatura y crítica latinoamericanas. Caracas. Facultad de Humanidades y Educación. Universidad Central de Venezuela: 1982, p. 67 et sqq.

PORTUONDO, José Antonio. Cuadernos Americanos, 3 (1948), 231-252.

- La historia y las generaciones. Santiago de Cuba. Manigua: 1958.

RAMA, Ángel. Diez problemas para el novelista latinoamericano. In: LOVELUCK, Juan (ed.) La novela hispanoamericana. Santiago de Chile. Universitaria: 1969. 
El boom establece expresamente un recorte empobrecedor de nuestras letras, que las deforma y traiciona. Zona Franca, 16 (1972).

. La construcción de una literatura. Originalmente en Marcha, 1041 (1960). 24-26. Reproducida en ANTELO, (ed.) Antonio Candido y los estudios latinoemericanos (2001), 21-34.

. Las máscaras democráticas del modernismo. Montevideo. Fundación Ángel Rama,:1985.

. Sistema literario y sistema social en Hispanoamérica. In: ALEGRÍA, Fernando (ed.) Literatura y praxis en América Latina. Caracas. Monte Avila: 1975, p. 81. RAMA, Ángel. La modernización literaria latinoamericana (1870-1910). La crítica de la cultura en América Latina, (eds. Saúl Sosnowski y Tomás Eloy Martínez). Caracas. Ayacucho: 1985, p. 87.

. Un proceso autonómico: de las literaturas nacionales a la literatura latinoamericana. Río Piedras, 5-6 (1974-1975).

ROCCA, Pablo. Notas sobre el diálogo intelectual Rama/ Candido. In: ANTELO, Raúl (ed.) Antonio Candido y los estudios latinoamericanos. Pittsburgh. Universidad de Pittsburgh. Instituto Internacional de Literatura Iberoamericana, 2001, p. 47.

ROJO, Grínor. En torno a la llamada generación de dramaturgos hispanoamericanos de 1927 más unas pocas observaciones sobre el teatro argentino moderno (Elementos de autocrítica). Revista de Crítica Literaria Latinoamericana, 16 (1982), 67-76.

ROJO, Grínor. Práctica de la literatura, historia de la literatura y modernidad literaria en América Latina. Crítica del exilio. Ensayos sobre literatura latinoamericana actual, 1989, p. 20 et sqq. SPERATTI PIÑERO, Emma Susana. (ed.) El descontento y la promesa. Seis ensayos en busca de nuestra expresión. Obra crítica. México e Buenos Aires: Fondo de Cultura Económica, 1960. pp. 252-253. 